\title{
Gender-Based Violence as A Driver of HIV Infections Among Adolescent Girls and Young Women in Kisumu, Kenya
}

\author{
Anthony Wainaina Ndungu \\ Projects Coordinator, NOPE International Institute, Nairobi, Kenya
}

\begin{abstract}
Gender Based Violence is a universal catastrophe affecting global health, and thus development and is a major human rights concern. This study's major objective was to establish what extent gender-based violence prevention influence performance of HIV prevention projects for young women and teenagers in Kisumu County. The study population constituted of teenage girls, and young women enrolled in HIV prevention projects implemented in Kisumu County for at least two years. Interviews were also conducted with key project implementers including project managers and monitoring and evaluation managers. Data collection for the study was done by utilizing data collection tools which included focused group discussion, structured questionnaires and an interview guide. 364 respondents were taken from 89,611 adolescents enrolled in HIV prevention projects using stratified random sampling technique. For descriptive data the study employed percentages, frequencies Arithmetic Mean as analytical tools of analysis. The Pearson's value and Linear Regression were manipulated as statistical tools for inferential statistics. To test the hypotheses, the Fisher $(F)$ test utilized. Descriptive statistics showed that gender-based violence prevention has a noteworthy effect on the production of HIV prevention projects for young women and adolescent girls in Kisumu County. The value of r2 was 0.452, indicating that gender-based violence prevention explained $45.2 \%$ of the change in the effectiveness of HIV prevention projects in Kisumu. The beta coefficient was 0.623, implying that gender-based violence had a noteworthy statistical impact on the performance of HIV prevention projects $(\beta=0.623, t=10.928$, $\mathrm{p}=0.000<0.05$ ).
\end{abstract}

Keywords : Gender-Based Violence, Adolescents Girls, Young Women, Project Performance

\section{INTRODUCTION}

Data from various countries show major discrepancies in efforts to step down the spread of new HIV transmissions. Over the last ten years some nations have succeeded in reducing HIV prevalence by more than $50 \%$ which is not the case for many African nations. According to a 2016 report of UNAIDS there has actually been a disheartening rise of new HIV infections in some African countries, UNAIDS (2016). The biggest burden in this is occurring in sub-Saharan Africa. China has achieved admirable results in addressing its HIV epidemic. The country's HIV history has been steady, with national negligence being the major facet in the metastasizing of the virus in the early 1990s. However, an important development in the past ten years and the national sensitization and response has reduced the epidemic through the country as well as better, standards of living for the victims of HIV|AIDS. China's HIV epidemic is characterized by a diminishing prevalence 0.037 percentage rate, while some areas have higher and more intensely unpleasant HIV prevalence rates. China is also 
challenged in offering increased targeted prevention programmes to majorly affected populations like young people.

HIV continues to hinder long term development in Africa. Sub Saharan Africa is gravely aggrieved, with nearly 70\% of the PLHIV globally. (WHO, 2015). Notwithstanding the number of new HIV infections has reduced, HIV prevalence remains worryingly high in some countries. Many counties in this region have shown considerable political and financial commitment to address the epidemic in the subSaharan region which has experienced a random scaling up of aversion, treatment, and comprehensive care services. However, most nations in this region still rely on grants and donations to fund their HIV response. (Bill, 2010). Most governments have shown efforts to make attempts to battle the epidemic in this region continually. Kenya HIV epidemic is ranked fourth across the globe concerning the population living with HIV that was estimated at 1.5 million victims in 2015.

On estimate, 36,000 persons died from AIDS-related sicknesses in the year 2015, although this figure is quickly declining from a 51,000 in the year 2010. To this date, more than 660,000 children have been orphaned by this plague. HIV prevalence rose to $10.5 \%$ in 1996 and had declined to $5.9 \%$ by 2015 . The decline was hugely influenced by the rapid imposition of HIV treatment, management, and care. (WHO, 2016). The SDG (Sustainable development goal) aim is to completely eradicate the AIDS epidemic by the year 2030 while consolidated global strategy aims to minimize cases of incidences occurring annually by $90 \%$ and the annual death rate occurring from AIDS-related causes by $80 \%$ (compared with 2010).

Amongst the most sanctioned social evils universally is the violence against women traversing religion, race, ethnicity, and social status. Sexual and genderbased violence (SGBV) is an exceptionally unsettling global concern. It has immense negative impacts on the female gender. SGBV can be defined as injurious and damaging acts committed against an individual's will based on their gender. This harmful act causes the deprivation of freedom for the individual either publicly or privately. It is more often than not that cases of sexual gender abuse are as a result of unequal gender relations in communities or as an occurrence of abuse of power. Jewkes argues that gender inequality is the cause of violence against women. $\mathrm{He}$ asserts that in the case of this harmful acts there is the involvement of a male and a female in which case the latter is the victim as the former has the upper hand in the relationship as dictating the society. Violence against women can be as a result of prejudice embedded within the laws of a society or prevailing societal believes and norms or take the form of sexual violence. This form of harm can cause dislocation and worse than be an experience of dislocation. Kenya is no exception, like the rest of the world, Sexual Gender Abuse is rooted in the societal structure that is keen on power differential amongst men and women.

Women are disadvantaged in that they have to stomach violence as a means of resolving conflict, as the society generally accepts it or is ore likely than not to turn a blind on the issue. Cornwall Andrea states: that the last decade has seen women increasingly get infected and affected by HIVAIDS in sub Saharan Africa. $61 \%$ of the African population living with HIV are women. UNAIDS states that its more likely than not that victims of gender based violence have thrice higher probability to be infected with the virus than those who have not been violated. According to statistics of a research carried out by the United Nations the probability of younger women being physically or sexually violated by an intimate is higher than that of older women. KDHS 
2014 , indicated that $38 \%$ of females aged between fifteen to forty-nine years have reported physical violence with $14 \%$ having eperienced sexual abuse.

\section{Statement of the problem}

Individuals infected with HIV, especially women and girls, are at a higher peril for GBV as a ramification of their status, and those experiencing GBV face a greater risk of HIV infection (Ellsberg and Betron 2010) - a risk more than 50 percent greater (World Health Organization [WHO] 2013). The intersection between the two creates a dual epidemic. Gender disparities can be biologically, structurally or socially caused and they can be as a result of stigma and prejudice affecting both males and females. Programs that address both GBV and HIV have the potential to make a greater impact on these epidemics than standalone programs that fail to consider this intersection. (UNITAID, 2016).

A recent study undertaken in Kenya shows that 32\% and $18 \%$ of women and men aged 18-24 respectively have reportedly faced sexual violence before they are of 18 years of age. According to UNICEF. Socioeconomic facets like unemployment, social class, financial ability, personal and societal values are determinants of gender-based violence. There is not one specific cause of SGBV but a combination of several societal and individual problems. GenderBased Violence incapacitates one on the aspect of a bargaining ability for safer sex or the ability to access their rights as human beings.

\section{Objective}

This study sought to explore to what extent gender based violence prevention influence performance of HIV prevention programs for adolescents in Kisumu County,

Kenya.

\section{Hypothesis}

The researcher hypothesized that:

Ho Gender based violence prevention has no significant influence on the performance of HIV prevention projects for adolescent girls and young women in Kisumu County, Kenya.

H1 Gender based violence prevention has a significant influence on the performance of prevention projects for adolescent girls and young women in Kisumu County, Kenya.

\section{LITERATURE REVIEW}

Amongst the most sanctioned social evils universally is the violence against women traversing religion, race, ethnicity, and social status. Sexual and genderbased violence (SGBV) is an exceptionally unsettling global concern. It has immense negative impacts on the female gender. SGBV can be defined as injurious and damaging acts committed against an individual's will based on their gender. It is more often than not that cases of sexual gender abuse are as a result of unequal gender relations in communities or as an occurrence of abuse of power. Jewkes argues that the reason women are an easy target for sexual and physical abuse is gender inequality. He asserts that in the case of this harmful acts there is the involvement of a male and a female in which case the latter is the victim as the former has the upper hand in the relationship as dictating the society. Violence against women can be as a result of prejudice embedded within the laws of a society, or prevailing societal believes and norms or take the form of sexual violence. This form of harm can cause dislocation and worse than be an experience of dislocation. Kenya is no exception, like the rest of the world, Sexual Gender Abuse is rooted in the societal structure that is keen on power differential amongst men and 
women. Women are disadvantaged in that they have to stomach violence as a means of resolving conflict, as the society generally accepts it or is are likely than not to turn a blind on the issue. HIV initiatives are largely concerned with finding ways to curb sexual violence. The institutionalizing of HIV post-exposure prophylaxis with the use of guidelines, such as WHO, PEPFAR GBV|HIV integration and the country's national standard for GBV, service delivery protocols and provider training has dominantly been used to address the issue of sexual violence in sub-Saharan Africa.

\section{Integration of GBV and HIV prevention}

GBV services through the delivery of prophylaxis, information, and linkages. The rising concern for the stigma associated with accessing facilities that offer help to survivors of GBV and SGBV has led to the development of models of sexual violence services that cater for the victims. One of the tested models includes a scheme for a microfinance model that embraces HIV and gender training. This model has gone beyond prevention of HIV to address issues that make one prone to the exposure of the virus addressing the issue of poverty reduction and increased women empowerment. These institutions seek to address issues of health, law, order, justice and deliver protection, support, and rehabilitation. The experience of abuse or the fear of it leads to detrimental effects on the prevention of HIV. For instance that the amenities for survivors of genderbased and sexual violence are limited, but even in the case of their availability a very small percentage of the affected in the community seek any form of care from the facilities. Research has shown that some factors attributed to this predicament and these include, fear of physical assault from partners and especially women from their husbands and stigmatization and fear of discrimination from the society. The sex subject is taboo in most sub-Saharan African families and is one that can cause physical punishment if ever brought up. Research shows that $60 \%$ of girls in an African family set up will not dare bring up the subject of condom usage for fear of violence.

A survey carried out by the Kenya Demographic and Health Survey in the year 2008 and 2009 showed that $39 \%$ of females aged fifteen and above had undergone a physical abuse. At least one in every four girls, as indicated by the study, had been sexually violated within a relationship. In another research in 2014, this time majoring on married, separated and divorced respondents KDHS gathered that at least 38\% women, 9\% men that were ever married had been physically abused by their partners. While $14 \%$ and $4 \%$ women and men aged 15-49 respectively had been sexually violated by their spouses. The matters of sexual and physical abuse are a grave issue in Kenya and one cannot be lightly handled if Kenya is to make any progress in eradicating the epidemic.

\section{Legal framework}

Gender Based Violence issue is one that is quite well covered in the constitution of Kenya. Laws, policies and regulations that aid the impediment and management of sexual and gender-based violation have been endorsed in various aspects that traverse the issue, including gender equality. These laws include the Sexual Offences Act (2006) which provides a comprehensive legal coverage of child prostitution and pornography, sexual assault, rape and attempted rape and compelled acts. Other legal frameworks covering the matter include the National Gender and Equality Commission Act (2011), to mention just but a few. Some of the legal framework majors particularly on women who have been the most affected by the phenomena. When these legal frameworks are considered gender-based violence violates about twenty-three Kenyan rights as stated in chapter four within bill of rights of the Kenyan 
Constitution. Magnitude of the effects of abuse is not one that can easily be ascertained. Individuals react differently and worse than these cases go unreported owing to fear of stigmatization. An abused individual will often more than not be in an environment that is more reactive than proactive against sexual genderbased violence.

\section{Theoretical Framework}

Three Theories guided this study; Health promotion theory, Theory of performance and sociological theories.

\section{Health promotion theory}

The Health promotion theory is majorly concerned with classifying and stipulating health promotion approaches rather than the elements affecting health outcome. It is primarily concerned in stipulating factors involving the most suitable methods of conveyance. Caplan stratifies health promotion in two angles, one from the point of modifying an individual's behavior or their environment and secondly the priorities articulated in health promotion by the victims, or experts.

It is a prescriptive approach propelled by the society's health determining factors, and as such aims at directing everyday activities to a healthy lifestyle. The affected communities are exposed to such an environment that encourages behavioral change for the achievement of a standard or better health. In WHO's 2000 strategy this theory was widely put into consideration.

Practically individually focused and expert-driven interventions are adopted in endeavors that promote healthy living including those addressing HIV infection. With the involvement of some of the affected communities and very few considerations of the environmental determinants of health promotion, this theory has barely been implemented. This collaborative approach is slowly being embraced while dealing with the vulnerable groups, a detrimental concern globally.

\section{Sociological theories}

Behavioral modifications are subject to a social set up and thus the importance of sociological theories. An individual's conduct is directly or indirectly related to the societies they are part of.

This theory, however, is wanting on the aspect of empirical evidence. A good illustration is the sexual orientation at socio cultural point of view. The sociological theory states that sexual identities are predominantly formed as individuals in given peer groups interact. Thus, the formation of gender roles and predominating ideologies like sexual ideologies where girls view sex as service to men and boys relate to the subject as a form of individual success. The primary principle behind this theory is that associations determine behavior.

\section{The Theory of Performance (ToP)}

Six foundational concepts are employed in the theory of performance in the attempt of behavioral modification, and they include, context, levels of knowledge and skill, identity status, and personal and fixed factors. Keenly interested in performance, the theory adopts teamwork and addresses the aspects of a sense of belonging as a contributing factor in behavioral change. Effective performance is subject to change and thus an object for evaluation to determine levels of production with the aim of improving the contingent factor.

\section{Conceptual Framework for the study}


Three key indicators of gender-based violence prevention were identified - sexual gender-based violence (SGBV); Emotional violence and physical violence.

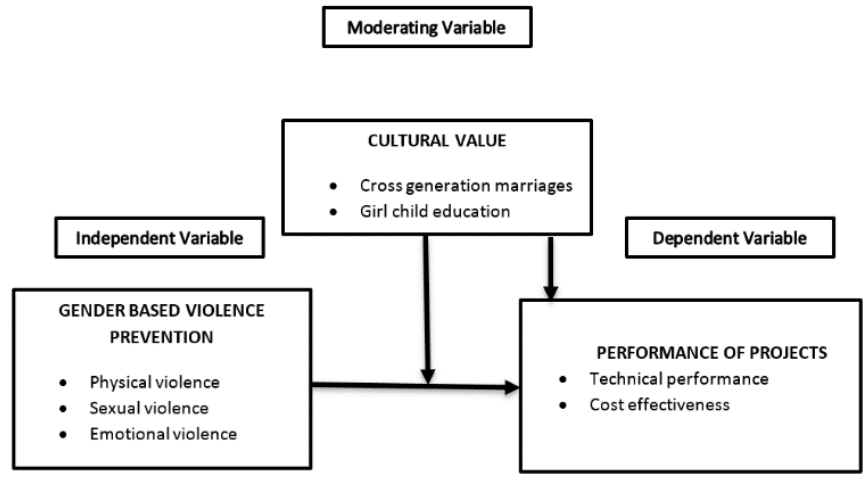

Figure 1 : Conceptual Framework of the Study

\section{RESEARCH METHODOLOGY}

The study adopted a pragmatic knowledge claim. According to Gakuu (2008), Pragmatic Knowledge Claim allows a researcher to seek knowledge and understanding of a situation under study, problems, and consequences using multiple approaches. A pragmatic approach is based on abduction reasoning that employs both induction and deduction reasoning to enable the use of both qualitative \& quantitative techniques to conduct the same study (Gakuu, 2008). Pragmatism perceives knowledge as being created and also based on the reality of experiences recorded. It claims that knowledge is born from activities, circumstances, and repercussions; it is concerned with applicability and way forward thus putting the problem as most important instead of methods (Gakuu et al., 2008). Alan (2009) posits that a researcher is guided by the ontological, epistemological, axiological, and methodological orientations. In this study, both quantitative and qualitative aspects of the performance of the project were investigated justifying the need for pragmatism.
The researcher in this case indulged in research to gathering and synthesis qualitative data.

\section{1) Research design}

Mixed method approach was used to enable data analysis to be done in a cross-sectional way.

In research methods, Sekaran (2003) indicates that a mixed mode approach can be classified into mixed models and mixed methods. Under a mixed model's approach, descriptive data analysis is undertaken independently followed by inferential data analysis. Under a mixed methods approach, both descriptive and inferential data analysis are conducted in parallel in an integrated way. Therefore descriptive, inferential and qualitative analysis could be conducted based on objective simultaneously.

\section{2) Sampling size}

In this study, respondents were drawn from the four organizations which have been in operation pursuing the stated objective in Kisumu County. Because the number of organizations is too small to be sampled, a census of the organizations is preferable rather than a sample (Mugenda \& Mugenda, 1999). The sample means consisted of key respondents were drawn from all the selected organizations. According to Huber (2004) determining a sample size in robust statistics a researcher is informed by the precision rate and the desired confidence level. Adopting a formula by Krejcie and Morgan (1979), will help chose a worthwhile sample size, i.e, adequate enough to offer accuracy.

$$
S=\frac{x^{2} N P(1-P)}{d^{2}(N-1)+x^{2} P(1-P)}
$$

Where;

$\mathrm{S}=$ needed sample size . 
$\mathrm{x}^{2}=$ table value of chi-square for 1 degree of freedom at the desired confidence level (3.84).

$\mathrm{N}=$ the population size $(89,611)$.

$\mathrm{P}=$ population size.

$\mathrm{d}=$ degree of accuracy expressed.

$$
\text { (3.84) (89611) (0.5) (1-0.5) }
$$

$$
S=\overline{0.0025(89611-1)+(3.84)(0.5)(1-0.5)}
$$

With the sample size determined, the proportional allocation was adopted to distribute the respondents among different organizations aiming to have at least 8 percent as shown in

Thus $358 / 89611 \times 100=8 \%$

\section{3) Sampling Procedure}

Determination of sampling methods and procedures helped this study focus to remain objective in choosing the sample free of biases. Different organizations were used from which respondents were picked from as strata. A sample was picked autonomously in a similar ratio to have a similar percentage of each total to ensure proportionality in representation from each strata. Random sampling ensured that every element in each strata has an equal chance of being chosen. Computer random numbers were generated for each category and respondents assigned these numbers randomly in proportion to the number of employees in each sector.

\section{Research instruments}

All the data collected was used to source for information. Secondary information was obtained mainly from desktop review and internet Search. Information Data obtained from the respondents was used to determine link between the variables in the study. Triangulation of research instruments was utilized with the aim of obtaining adequate information. Self-administered structured questionnaires and an interview guide were employed in the collection of data as instruments of research. A research instrument, in this case, is a device that the researcher used to collect data. To obtain quantitative data a structured questionnaire was utilized while a guided interview aided in gathering qualitative data. The application of multiple instruments was important for enhancing the validity of data obtained and minimizing the possibility of experiencing interviewer biases. Such biases often arise from non-verbal cues that may influence participants to give misleading responses by reporting positive aspects even where negative aspects are predominant (Jaeger, 1984).

\section{Reliability of instruments}

The study applied, test-retest technique. It involves applying a similar test twice to a similar group of respondents after a particular period has expired between the two tests (Coopers and Schindler, 2003). This gauge was chosen because the respondents being interviewed were expected to voluntarily be willing to respond to the questions in both times.

\section{Ethical Issues}

Written communication seeking permission to carry out research was done and letters dispatched to the targeted respondents in appropriate offices. The respondents were required to sign the letters of consent before the actual data collection commencement. The respondents were assured that disclosures would not be made on the identity of the respondents. As such, the respondents were requested not to indicate their names on the questionnaires and disclosure of the findings was availed on request. In the occurrence of any detrimental effects arising as a repercussion of the 
research to the institution or individuals under study, the researcher committed to making compensations.

\section{FINDINGS AND DISCUSSIONS}

A sample size of 358 respondents from a research population of 89,611 adolescents in Kisumu County as recorded in the most recent census was used in the study. 352 filled tools were returned which was a return rate of $96.7 \%$ which was considered adequate for this study. Richardson (2005) indicated that a response rate of $60 \%$ and above is both desirable and achievable in social sciences though in some cases it could go lower.

\section{Categories of Respondents by Level of Education}

The options that were provided in this item were: primary level, secondary level, and tertiary level. Table below shows that the highest percentage of respondents were either in secondary school or had completed secondary level of education (54.5\%); 382\% had acquired a primary level of education while 7.3\% of those interviewed had tertiary education(Polytechnic, college or university). The responses were as shown in Table below

\section{Distribution of respondents by level of education}

\begin{tabular}{|c|c|c|}
\hline Level of Education & $\mathrm{F}$ & $\%$ \\
\hline Primary & 137 & 38.2 \\
Secondary & 195 & 54.5 \\
Tertiary & 26 & 7.3 \\
& & \\
\hline Total & $\mathbf{3 5 8}$ & $\mathbf{1 0 0}$ \\
\hline
\end{tabular}

\section{Distribution of respondents by marital status}

Options provided required them to indicate whether they were single, married, divorced or separated. This information was considered important to determine help understand the dynamics of different respondents in a peer-based setting. The results were as shown below

\section{Distribution of respondents by marital status}

\begin{tabular}{lcc}
\hline Marital Status & F & $\%$ \\
\hline Single Married & 278 & 77.7 \\
Divorced/Separated & 44 & 12.3 \\
& 31 & 8.7 \\
Widowed & 5 & 1.3 \\
& & 100.0 \\
\hline
\end{tabular}

The results show that $77.7 \%$ of respondents interviewed were single and had never been married. Most of the respondents in this category were school going. Out of the total population questioned 12.3\% indicated that they were married. This information would later be used by the researcher to establish the influence of early marriages among adolescents in the region. A small percentage (8.0\%) indicated that they had earlier been married but were now divorced or separated. Others indicated that they were widowed $(2.0 \%)$

Distribution of respondents by the duration of engagement in the project

The duration an individual had been involved in the projects was considered important in appreciating the project performance. The data were clustered and categorized as shown below 


\begin{tabular}{|c|c|c|c|c|c|}
\hline \multicolumn{3}{|c|}{$\begin{array}{l}\text { Distribution of respondents by the duration of } \\
\text { engagement in the project }\end{array}$} & \multicolumn{3}{|c|}{$\begin{array}{l}\text { Normality test } \\
\text { This study used the Shapiro-Wilk test since } \\
\text { sample size } n=3 \text { to } 2000 \text { i.e } 352 \text {. In this test stati }\end{array}$} \\
\hline Duration of engagement & Frequency & Percentage & \multicolumn{3}{|c|}{ stands for W. Following a SPSS run, the follow } \\
\hline 0 months -3 months & 45 & 12.6 & \multirow{2}{*}{\multicolumn{3}{|c|}{ variables and dependent variable as shown }} \\
\hline 4 months -6 months & 12 & 3.4 & & & \\
\hline 7 months - 9 months & 80 & 22.3 & \multicolumn{3}{|l|}{ Normality Test } \\
\hline 10 months -12 months & 150 & 41.9 & \multirow{2}{*}{\multicolumn{3}{|c|}{ Shapiro-walk }} \\
\hline Ahove 12 Months & 63 & 176 & & & \\
\hline \multirow{2}{*}{ Non- responsive } & \multirow[b]{2}{*}{8} & \multirow[b]{2}{*}{2.2} & Variables & Df & Sig. \\
\hline & & & Gender-based & 182 & .003 \\
\hline Total & 358 & 100 & influence & & \\
\hline
\end{tabular}

Research findings showed that 45(12.6\%)had been engaged for utmost three months while $3.4 \%$ had been involved for a period between 4 to 6 months. This result implies that $22.3 \%$ of the respondents had been involved in the project for a period between 7 9 months. Although the majority (41.9\%) of the respondents had been involved for 12 months or less in the projects, this was not an indicator of the respondent's experience in the projects. Interviews conducted in this study indicated that many respondents had worked with similar projects for more than three years which was considered in this study sufficient to make objective responses on the performance of HIV prevention projects.

\section{Tests for Statistical Assumptions and Analysis of Likert-Type Data}

Pedace (2013) indicates that conflict in statistical assumptions can nullify them. Tests conducted included normality test, multicollinearity and singularity. Also Type I \& II errors which occur due to the wrong interpretation of results during tests of various statistics were controlled. Also, use of Likert scale in analysis is elaborated in this section.

$\begin{array}{llll}\begin{array}{l}\text { Cross-generational } \\ \text { marriages }\end{array} & .972 & 182 & .001 \\ \begin{array}{l}\text { Performance of } \\ \text { projects }\end{array} & .963 & 182 & .000\end{array}$

All the statistics in the test $(\mathrm{W})$ were above 0.96 . The list was 0.963 , and the highest was 0.997 . None of the variables had $\mathrm{W}$ statistics $=1$. Therefore none was a perfectly normal distribution, but the scores were significantly closer to 1 which was acceptable since a perfectly normal distribution is rarely achievable.

\section{Likert Scale as an Interval Measure}

Likert scale types of questions were used in the study. These are differentiated as Likert item; when an item is used to measure a single variable and Likert scale; when some items are arranged as a group intended to measure a single variable (Brown, 2011). A composite score was used in analysis and decision rules after analysis of mean scores were guided by the logical equal levels of the score approximated to the first decimal point in line with equidistance arguments (Carifio and Rocco, 2007; Bertram, 2007; Lantz, 2013). This study used one verbal anchor; 1=Strongly 
Disagree (SD); $2=$ Disagree (D); $3=\operatorname{Neutral}(\mathrm{N}) ; 4=$ Agree (A); 5= Strongly Agree (SA) Therefore the judgment rule followed this argument; Strongly disagree would be for values lying between $1<$ S.D $>1.8$; Disagree for values between $1.8<\mathrm{D}>2.6$; Neutral for values between $2.6<\mathrm{N}>3.4$; Agree for values between $3.4<A>4.2$; Strongly Agree for values between $4.2<$ S.A $>5.0$. This creates a scale that has an equidistance of 0.8 .

Correlations coefficient was used to measure relationships. Decision rule followed Cohen (1988) guiding that $\mathrm{r}$ ranging between $.10-.29$ means weak correlation; $\mathrm{r}$ - ranging between .30 - .4.9 means medium correlation and $\mathrm{r}$ - ranging between .50 to 1.0 means strong correlation. Positive or negative sign indicates the direction of the relationship, never the strength. These guidelines were also used by Shirley, Stanley, and Daniel (2005).

\section{Correlation Analysis}

\section{Correlation analysis results}

\section{Control of Type I Error and Type II Error}

For statistical findings to be valid, a researcher has to control Type I \& II errors which occur due to wrong interpretation of results during tests of various statistics. The former occurs when null hypothesis gets accepted in place of rejection while the vice versa is true for occurrence of the latter(Larry, 2013). In this study, to control type 1 error, a confidence level of $95 \%$ was used implying that the standard variate was 1.96 and the sample proportion $(\mathrm{p})<=$ 0.05 as recommended by Larry (2013). Type II error was controled by choosing a sizeable sample as recommended by Sekaran's (2003) sample size criterion.

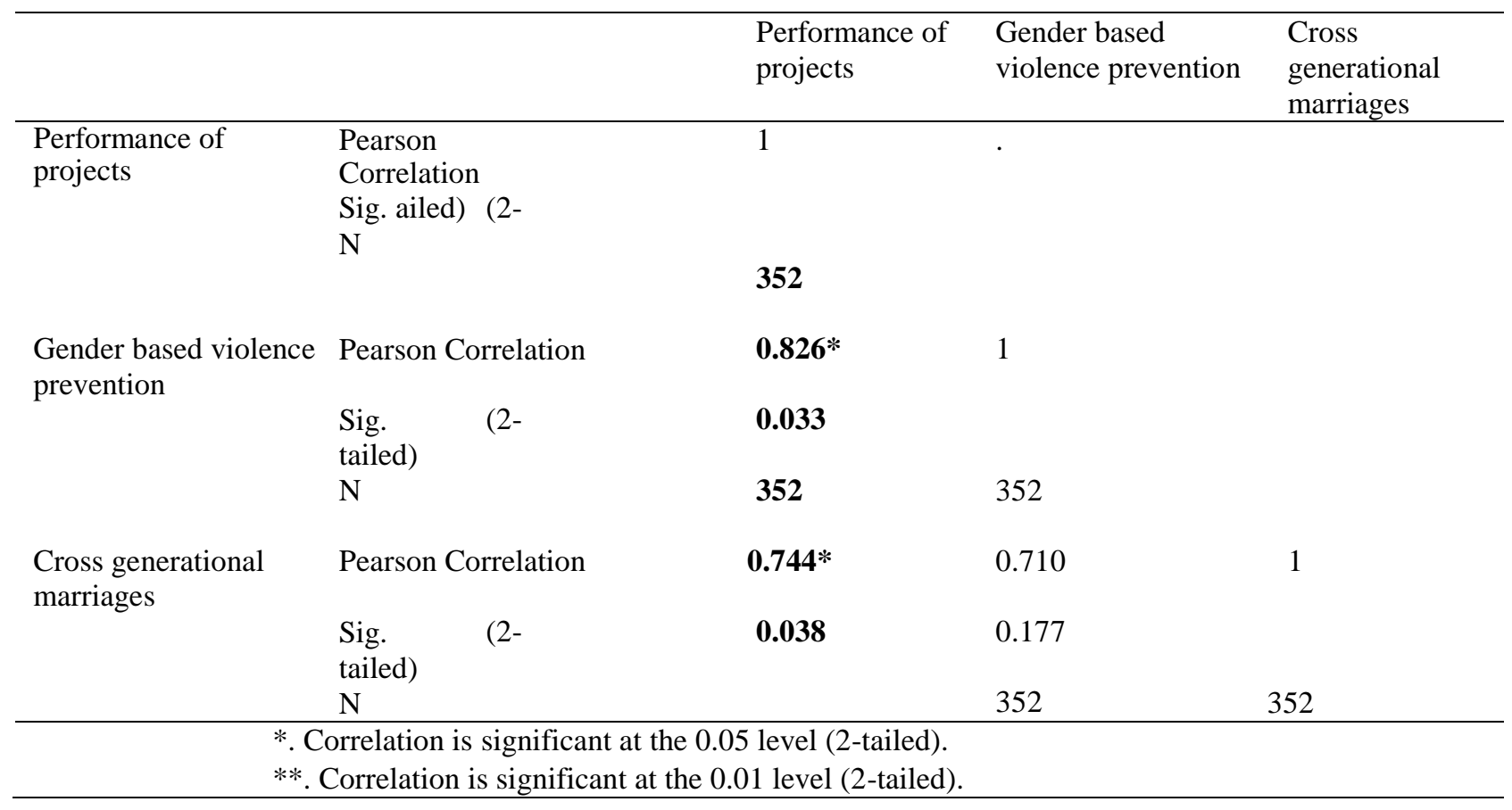


The table aove shows the correlation analysis results of the dependent and indepedent variables. To determine correlation between the variables, Pearson Correlation was used.

\section{Tests of Hypothesis}

Hypothesis testing was done to establish the statistical significance of gender based violence prevention on the performance of projects. Testing was based on ordinary least squares (OLS) regression results, under OLS regressions, the values, R, R2, Fratio, "t-values" and "p-values" were acquired. The $\mathrm{R}$ value shows the magnitude of the relationship, R2(coefficient of determination) value indicates the extent to which change in independent variable

\section{Models for testing the hypothesis}

explain indicators of the dependent variable (goodness of fit), F-value indicates the statistical influence of the whole model, $t$-values represent the influence of individual variables, Beta values show the influence of the independent on the dependent variable and "p-value" indicates the confidence level at $95 \%$ or 0.05 significant level. In determining the significance, $\mathrm{F}$ test was used; where the general rule is If $\mathrm{F}$ Calculated $<\mathrm{F}$ Critical null hypothesis is accepted otherwise rejected.

The decision rule adopted was; if "p-value" $<\alpha$, reject the null hypothesis otherwise accept. The models in these tests focus on establishing the influence of the independent variables on the dependent variable but not choice of model.

\begin{tabular}{|l|l|l|}
\hline \multicolumn{1}{|c|}{ Objective } & \multicolumn{1}{|c|}{ Hypothesis } & \multicolumn{1}{c|}{ Model for Hypothesis testing } \\
\hline $\begin{array}{l}\text { To determine the extent to } \\
\text { which gender-based violence } \\
\text { prevention influence the } \\
\text { performance of HIV } \\
\text { prevention projects for } \\
\text { adolescent girls and young } \\
\text { women in Kisumu County, } \\
\text { Kenya }\end{array}$ & $\begin{array}{l}\text { Hypothesis 1; } \\
\text { H1: Gender-based violence } \\
\text { prevention has no significant } \\
\text { influence on the performance of } \\
\text { HIV prevention projects for } \\
\text { adolescents and girls and young } \\
\text { women in Kisumu County, Kenya. }\end{array}$ & $\begin{array}{l}\mathrm{y}=\mathrm{a}+\mathrm{p}_{1} \mathrm{X}_{1}+\mathrm{e} \\
\mathrm{y}=\text { project performance } \\
\mathrm{a}=\text { constant } \\
\beta_{1}=\text { Beta coefficient } \\
\mathrm{X}_{1}=\text { Gender based violence prevention }\end{array}$ \\
$\mathrm{e}=$ error term
\end{tabular}

Ho: Gender-based violence prevention has no major influence on performance of HIV prevention programs for adolescents and girls and young women in Kisumu County, Kenya.

The hypothesis aimed at establishing whether gender-based violence prevention has a major impact on the performance of HIV prevention programs in Kisumu. A composite index of performance of HIV prevention projects was used as the dependent variable. This composite was of cost-effectiveness, technical performance and beneficiaries' satisfaction of services. The independent variable was a composite index of gender-based violence prevention, in which it composes sexual violence, emotional violence, and physical violence. 
To test this hypothesis a regression model of the form:

$\mathrm{y}=\beta 0+\beta 1 \mathrm{X} 1+\varepsilon$ was estimated, where:

$\mathrm{y}=$ Performance of HIV prevention projects

$\beta 0=$ Constant

$\beta 1=$ Beta coefficient

$\mathrm{X} 1=$ Gender-based violence prevention

$\varepsilon=$ Error term

$r$ value of 0.826 indicates a very positive influence of gender-based violence prevention on the performance of HIV prevention projects. The coefficient of determination (adjusted R-Square) statistics of 650 implies gender-based violence prevention explains $65.0 \%$ of the performance of HIV prevention projects, while $35.0 \%$ of performance is explained by other factors other than gender-based violence prevention. The adjusted $\mathrm{R}^{2}$ is used instead of $\mathrm{R}^{2}$ as it takes care of the adjustments in the degrees of freedom. The Durbin-Watson Statistic of 2.590 showed the absence of autocorrelation as such indicating the model was statistically good.

Table : Regression results of the influence of behavioral interventions on the project's performance

\begin{tabular}{lllcc}
\hline Model & $\begin{array}{l}\text { Coefficients } \\
(\boldsymbol{\beta})\end{array}$ & Std. Error & $\mathrm{Z}$ value & $\mathrm{P}>\mathrm{Z}$ \\
\hline (Constant) & $14.434^{* * *}$ & 4.832 & 3.129 & 0.004 \\
$\begin{array}{l}\text { Gender based } \\
\text { violence }\end{array}$ & $.468^{* *}$ & .147 & & 0.012 \\
\hline
\end{tabular}

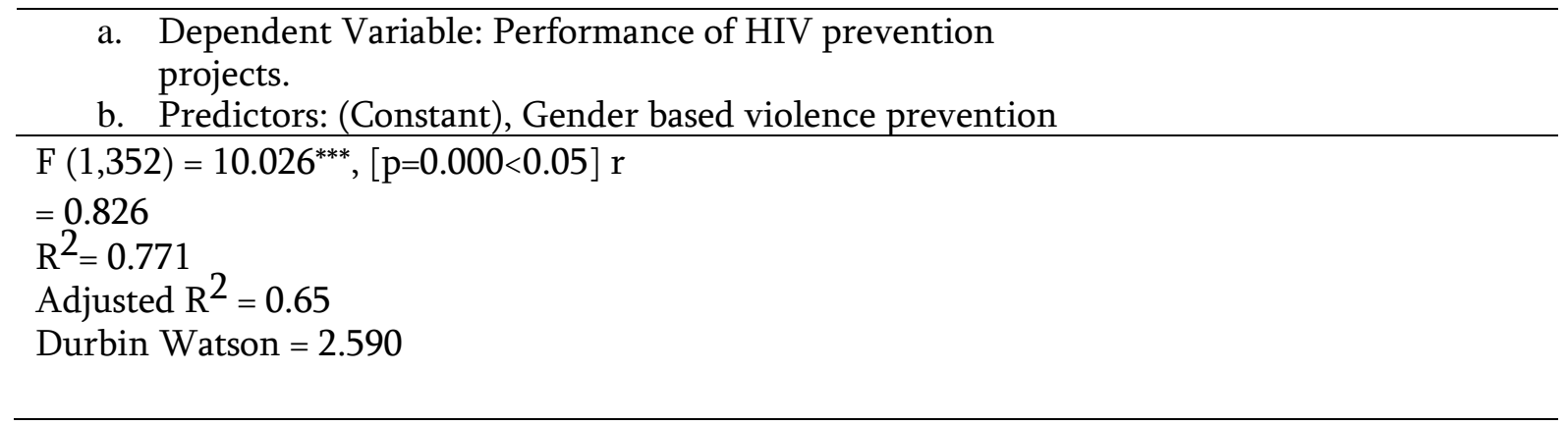

The F-ratio of 10.026 is statistically significant at 5\% $[\mathrm{p}=0.000<0.05]$ implying that Gender-based violence prevention has a consequential effect on how HIV prevention projects for teenagers in Kisumu County in Kenya. Thus, from the regression results, the null hypothesis was rejected. Based on previous studies conducted on the influence of GBV prevention on the performance of projects the researcher concludes that the findings agree with various former studies (King R, 2008: Stephenson et al., 2014; Peterman 2014 \& Nicholl et al., 2006). These studies suggest that gender-based violence prevention is important in improving performance of projects. A positive correlation was established between the performance of HIV prevention projects and gender based violence prevention in this research, with $[\mathrm{r}=.826, \mathrm{n}=352$, $\mathrm{p}=.046<0.05]$, the Pearson correlation was very close to 1 , implying gender-based violence prevention is perceived to contribute to the performance of HIV prevention projects highly. 


\section{CONCLUSION AND RECOMMENDATIONS}

Whereas the study sought to know the relationship between gender-based violence prevention and performance of projects, it proved quite a difficult task establishing working indicators for the beneficiaries of the reserch. Owing to the obstacles faced it is of essence to conclude that for strategy concerns, executers of projects need to put to use school settings for significant information and as such achieve performance improvement for projects. Gender inequality links gender-based violence and HIV as one of two indirect pathways that have an even greater impact on HIV transmission than the direct pathways. In societies where patriarchy and unequal gender norms are deeply entrenched, the probability of men committing sexual violence or paying for sex, and are less likely using condoms is higher.

\section{REFERENCES}

[1]. Addo, Victor N. 2005. "Pregnant women's knowledge of and attitudes to HIV testing at Komfo pital, Kumasi," Ghana Medical Journal 39(2): 50-54.

[2]. Allen, Susan, Jareen Meinzen-Derr, Michele Kautzman, et al. 2003. "Sexual behavior of HIV discordant counseling and testing," AIDS 17 (5): 733-740. Angotti, Nicole. 2010. "Working outside the box: How HIV counselors in sub-Saharan Africa norms," Social Science \& Medicine 71(5): 986-993.

[3]. Angotti, Nicole C. 2012. "Testing differences: The implementation of Western HIV testing norms Culture, Health \& Sexuality 14(4): 365-378.

[4]. Bakke, W.E. (1959). Concept of social organization. pp. 16-75, in: Haire, M. (ed), Modern Organization Theory. New York, NY: John Wiley.
[5]. Balogun, M. J. (2003). Performance Management and Agency Governance for Africa Development: The search for common cause on Excellence in the Public Service. UNCEA, Addis Ababa.

[6]. Balogun, M. J. (2008). Performance Management and Agency Governance for Africa Development: The search for common cause on Excellence in the Public Service. UNCEA, Addis Ababa. Bain George Grantham. (1927). An Attitude on Attitude Research. American Journal of Sociology, 33 (1927-28): 940-957.

[7]. Bankole, Akinrinola, Ann Biddlecom, Georges Guiella, Susheela Singh, and Eliya Zulu. 2007. Edge and information sources of very young adolescents in four sub-Saharan African countries," Reproductive Health

[8]. Barzilai, K. (2011). Organizational theory. Western Reserve University

[9]. Connell, J. P., \& Kubisch, A. C. (1998). Applying a theory of change approach to the evaluation of comprehensive community initiatives: progress, prospects, and problems. New Approaches to Evaluating Community Initiatives, 2(15-44).

[10]. Cooper, D. R., Schindler, P. S., \& Sun, J. (2006). Business research methods. Retrieved from http://sutlib2.sut.ac.th/sut_contents/H139963.pdf

[11]. Ferrand RA, Corbett EL, Wood R, et al. (2009) AIDS among older children and adolescents in Southern Africa: projecting the time course and magnitude of the epidemic. AIDS 2009; 23(15):2039-2046.

[12]. Glanz, Karen; Barbara K. Rimer; K. Viswanath (2008). Health behavior and health education: theory, research, and practice. (PDF) (4th ed.). San Francisco, CA: Jossey-Bass.

[13]. Glanz, Karen; Bishop, Donald B. (2010). "The role of behavioral science theory in development and implementation of public health interventions". Annual Review of Public Health.

[14]. International. Retrieved from http://books.google.com/books?hl=en\&lr=\&id=8c6 gkbKi- 
[15]. Janz, Nancy K.; Marshall H. Becker (1984). "The Health Belief Model: A Decade Later". Health Education \& Behavior.

[16]. Johnson, R. B., \& Onwuegbuzie, A. J. (2004). Mixed methods research: A research paradigm whose time has come. Educational Researcher.

[17]. Johnson, R. B., Onwuegbuzie, A. J., \& Turner, L. A. (2007). Toward a definition of mixed methods research. Journal of Mixed Methods Research.

[18]. Joint United Nations Programme on HIV/AIDS. (2006) Report on the global HIV/AIDS epidemic. Geneva, Switzerland: UNAIDS, 2006.

[19]. Levin, K. A. (2006). Study design III: Crosssectional studies. Evidence-Based Dentistry, 7(1), 24-25. doi:10.1038/sj.ebd.6400375

[20]. Lincoln, Y. S. (1985). Naturalistic inquiry (Vol. 75). Sage. Retrieved from http://books.google.com/books?hl=en\&lr=\&id=2o A9aWlNeooC\&oi=fnd\&pg=PA

[21]. Lisko, S. A., \& O'DELL, V. (2010). Integration of theory and practice: Experiential learning theory and nursing education. Nursing Education Perspectives, 31(2), 106-108.

[22]. Mackay, K. R. (2007). How to Build Monitoring and Evaluation Systems to Support Better Government. World Bank Publications.

[23]. Mackenzie, N., \& Knipe, S. (2006). Research dilemmas: Paradigms, methods and methodology. Issues in Educational Research, 16(2), 193-205.

[24]. MacKinnon, D. P., Lockwood, C. M., Hoffman, J. M., West, S. G., \& Sheets, V. (2002). A comparison of methods to test mediation and other intervening variable effects. Psychological Methods, 7, 83-104. 144

[25]. MacKinnon, D.P. (1994). Analysis of Mediating Variables in Prevention and Intervention Research. Scientific Methods for Prevention Intervention Research. NIDA Research Monograph 139, 127-153

[26]. demographic and epidemiologic analysis. AIDS 1994; 8:995-1005
[27]. Padian, N.S. et al (2008) 'Biomedical interventions to prevent HIV infection: evidence, challenges, and way forward' The Lancet 372(9638):585-599

[28]. Panel on Antiretroviral Guidelines for Adults and Adolescents. (2012) Guidelines for the use of antiretroviral agents in HIV-1-infected adults and adolescents. Washington, DC: US Department of Health and Human Services; 2012.

[29]. Ponterotto, J. G. (2005). Qualitative research in counseling psychology: A primer on research paradigms and philosophy of science. Journal of Counseling Psychology, 52(2), 126.

[30]. Rosenstock, Irwin (1974). "Historical Origins of the Health Belief Model". Health Education \& Behavior.

[31]. Rosenstock, Irwin M.; Strecher, Victor J.; Becker, Marshall H. (1988). "Social learning theory and the health belief model". Health Education \& Behavior.

\section{Cite this article as :}

Anthony Wainaina Ndungu, "Gender-Based Violence as A Driver of HIV Infections Among Adolescent Girls and Young Women in Kisumu, Kenya", International Journal of Scientific Research in Science and Technology (IJSRST), Online ISSN : 2395-602X, Print ISSN : 2395-6011, Volume 6 Issue 2, pp. 665-678, March-April 2019. Available at doi : https://doi.org/10.32628/IJSRST1962129 Journal URL : http://ijsrst.com/IJSRST1962129 